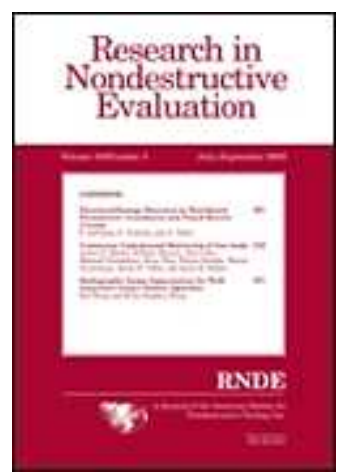

\title{
OPTICAL SCANNING FOR STRUCTURAL VIBRATION MEASUREMENT
}

\begin{tabular}{|c|c|}
\hline Journal: & Research in Nondestructive Evaluation \\
\hline Manuscript ID: & URND-2010-0008.R1 \\
\hline Manuscript Type: & Original Paper \\
\hline $\begin{array}{r}\text { Date Submitted by the } \\
\text { Author: }\end{array}$ & $\mathrm{n} / \mathrm{a}$ \\
\hline Complete List of Authors: & $\begin{array}{l}\text { Ferrer, Belen; Universidad de Alicante, Departamento de Ingeniería } \\
\text { de la Construcción } \\
\text { Espinosa, Julián; Universidad de Alicante, Instituto Universitario de } \\
\text { Física Aplicada a las Ciencias y a las Tecnologías } \\
\text { Pérez, Jorge; Universidad de Alicante, Instituto Universitario de } \\
\text { Física Aplicada a las Ciencias y a las Tecnologías } \\
\text { Ivorra, Salvador; Universidad de Alicante, Departamento de } \\
\text { Ingeniería de la Construcción } \\
\text { Mas, David; Universidad de Alicante, Instituto Universitario de } \\
\text { Física Aplicada a las Ciencias y a las Tecnologías }\end{array}$ \\
\hline Keywords: & Image Processing, Impact, Measurement, Non-contact, Optical \\
\hline
\end{tabular}

\section{(5) ScholarONE" \\ Manuscript Central}


OPTICAL SCANNING FOR STRUCTURAL VIBRATION MEASUREMENT

\author{
Belén Ferrer $^{\mathrm{a}^{*}}$, Julián Espinosa ${ }^{\mathrm{b}}$, Jorge Pérez ${ }^{\mathrm{b}}$, Salvador Ivorra ${ }^{\mathrm{a}}$, David Mas ${ }^{\mathrm{b}}$ \\ ${ }^{a}$ Universidad de Alicante, Departamento de ingeniería de la Construcción, San Vicente \\ del Raspeig, Alicante 03690, Spain \\ ${ }^{\mathrm{b}}$ Universidad de Alicante, Instituto Universitario de Física Aplicada a las Ciencias y a \\ las Tecnologías, San Vicente del Raspeig, Alicante 03690, Spain \\ *Corresponding author: Tel.: +34 965903400, Ext.: 1167; Fax.: +34 965903678
}

\begin{abstract}
High speed cameras are often used for monitoring impacts and fast dynamic processes on structures. However, quantitative information about these processes is usually obtained through other means like accelerometers or Doppler vibrometers. In this paper, we show that a proper arrangement of the experiment and the camera allows non contact measurement of the characteristics of the main displacement mode (amplitude, frequency and attenuation). An application is given for the analysis of structure damages after low speed car impacts. The method is low cost, fast and accurate, and it permits direct visualization and measurement of the movement of the vibrating body.
\end{abstract}

\title{
KEYWORD
}

Image Processing, Impact, Measurement, Non-contact, Optical 


\section{INTRODUCTION}

Monitoring of vibrations and displacements of structures under dynamic excitations or impacts is a hot topic in structural engineering. Measurement of the dynamic response to ambient excitation contributes to know the condition of structures and to identify possible damage [1]. Furthermore, the maximum displacement under dynamic loading allows defining the equivalent static load as the load that statically applied provokes the same displacement on the structure [2]. This magnitude is commonly used as a parameter to design safe structures under dynamic loading [3,4]. However, in spite of its usefulness, the list of accurate displacement sensors is quite short.

Traditional structural displacement sensors, such as linear variable differential transformers (LVDT) and dial gauges can accurately measure the displacement of a point in the structure and in any direction. Unfortunately, the sensors need a stationary platform near the structure with their two ends rigidly fixed to the reference and the measured point, respectively. If this fixation is not strong enough, the probe will loose contact with the surface during a hard impact, providing false position information. Furthermore, the placement of such auxiliary construction is not always possible, thus impeding accurate displacement measurements.

In principle, dynamic displacement can be also obtained by double integration of a corresponding acceleration time history with some corrections [5]. Although this approach is theoretically right, in practice, direct integration does not provide good results and further considerations are often needed [6,7]. Moreover, acceleration amplitude is proportional to the square of the angular frequency and thus, signal due to high frequency modes with low displacement amplitude can mask results of interest. We will come back on this issue below. 
Other devices that seem to be very attractive for such applications are interferometric sensors, such as laser vibrometers or high speed radar interferometry. These devices can be used to no contact measure of both small and large displacements. Their accuracy and dynamic range is also high [8-11] and thus, they can be used in a high variety of applications [12-14]. Unfortunately, these devices tend to be very expensive, what makes that they are not cost-effective for many applications. Besides, the GPS is used to measure dynamic displacement but its accuracy is around $15 \mathrm{~mm}$, which makes it only suitable for monitoring of very large structures [15].

Optical and vision-based systems for measuring displacement offer a good alternative to traditional sensors [16-18]. Fast development of the electronics and computer technology has helped to decrease the price of such technologies and thus, its use is becoming more and more popular. Examples of such optical instrumentation are high resolution cameras in both spatial and temporal domains.

This paper focuses on monochrome high speed CCD video cameras. We propose to use a fast imaging system to capture the displacement of a vibrating column. The developed method allows a direct visualization of the movement and, after image processing, it is possible to measure the amplitude, damping and frequency of the vibration. The cost of the whole system is less than $3000 €$ and it does not require of any special hardware, aside of a fast enough camera $(200 \mathrm{~Hz})$.

Our method was tested on a steel column under a lateral impact. The lateral impact was provided by a steel sphere holding by a thread at the highest part of the column. A special target was attached in the lateral part of the column, at the height of the impact, so that vibrations in the direction of the impact can be measured. Our measuring device is composed by a high speed camera and different accelerometers attached to the column. Although accelerometers do not provide direct information about 
displacements, they can register the frequency of the vibration modes which are going to be checked with those obtained with the camera.

In the following sections, we make a brief mathematical description of the problem, together with a numerical model of our particular problem. Afterwards, we describe the image capturing and processing methods in order to obtain the displacements in the column. Our results are compared both with those obtained through the accelerometers and with the numerical calculation based on a finite element model for this problem.

\section{PROBLEM DESCRIPTION}

The aim of this paper is to propose an alternative low cost method to measure the displacements in a column due to an impact. To this end, we selected a $2.1 \mathrm{~m}$ length steel column composed by two welded UPN-100 beams forming a hollow column. The two ends of the column are fixed to the floor and to one larger steel structure, as can be seen in figure 1.

A steel ball of $0.44 \mathrm{~kg}$ was used as projectile for the impact. This ball was mounted in a pendulum of $1.5 \mathrm{~m}$, hanging from the upper part of the column. By releasing pendulum form a fixed height, we ensure the repeatability of the experiment.

The column vibration after the impact was registered with an accelerometer located at the impact height in the opposite side of the column. At the same height, in a lateral side of the column, an image target of $5 \mathrm{~cm}$ of diameter was attached. The movement of the target was registered by a high speed (X-PRI AOS Technologies AC) working at 1000 fps with a spatial resolution of $800 \times 560$ located at $1 \mathrm{~m}$ from the column (see figure 2 ). In order to have a sharp and luminous image, a Navitar Zoom 7000 Macro Lens was attached to the camera. The camera was connected to a laptop through an Ethernet connection, so no special acquisition devices were needed. 


\section{IMAGE PROCESSING TECHNIQUES}

Seven impacts were recorded with the camera and the accelerometer. The target was designed as a round circle with alternative black and white quadrants (see figure 2). The camera acquired sequences of 3 seconds for each impact that were saved and then processed off-line with our own software developed in Matlab (The Mathworks inc.). All image processing is done on binary images, so the first step consists in selecting a proper threshold value. Since the image is composed of black and white areas, any intermediate gray value will provide correct results, so the mean value of the first frame in the sequence was selected and the rest of them were thresholded according to this parameter.

Processed images from the video sequence are arranged in a stack thus forming a 3D hypermatrix. The procedure is similar to that used in tomography. Such structure allows $3 \mathrm{D}$ reslicing of the sequence thus getting different time sections of the image, as it is shown in figure 2. Depending on the specialization field, these sections are also called M-scans or kymograms. In this particular case, in order to analyze the movement of the target in the impact direction, we select a horizontal scan line crossing the vertical border between two consecutive quadrants. So obtained sections are disposed as rows in a new image matrix, which allow a direct observation of the temporal sequence thus making clear the movement dynamics (figure 3).

The reader should notice that this first step allows direct visualization of the column vibration. Although we used some pre-processing of the image, direct reslicing of the video sequence can be done by using free software like ImageJ [19], an open source program devoted to numerical processing of biological and tomographic images. This 
simple processing provides a fast and immediate analysis of the dynamic process previous to any numerical filtering and processing of the signal.

A quantitative estimation of the amplitude, frequency and damping of the vibration can be calculated from the obtained scan. Notice that every binary segment forming the rows of the time sequence can be considered as a Heaviside step function. The derivative of such function is a delta function which localizes the position of the border and thus, allows obtaining relative position in pixels of the target in each frame. The conversion from pixels $(\mathrm{px})$ to millimeters can be easily done since the real size of the target is known and, from the first frame, we can directly obtain the relation between real and image sizes. This relation depends on the CCD structures and the zooming system. In our case this conversion value is $50 \mathrm{px} / \mathrm{mm}$, thus giving an accuracy of 0.02 $\mathrm{mm}$.

\section{NUMERICAL SIMULATION THROUGH FINITE ELEMENTS MODELS}

The problem under study has been implemented in a Finite Element Model (FEM) and a modal and dynamic analysis was performed. The FEM was created in LSDYNA code [20]. The column was modelled with SOLID element. This type of element is hexahedral shaped and is defined by 8 nodes with 3 degrees of freedom per node. The size of the elements was 10x10x50 mm, thus the column model having 2077 elements with 3506 nodes. The steel was modelled as an elastic-plastic material with a Young modulus of $210 \mathrm{GPa}$, Poisson modulus 0.3 , density $7850 \mathrm{~kg} / \mathrm{m}^{3}$ and yield strength 275 MPa. The column was modelled as a two pinned beam. A modal analysis was performed to find the first 20 modes and to validate the column model thought comparison with analysis of data recorded. The frequencies (in Hertz) of these modes are shown in table 1. 
In order to perform the dynamic analysis, a spherical ball was modelled hanging by a thread of $1 \mathrm{~mm}$ of diameter fixed to the upper part of the column. The ball was meshed with 4 nodes tetrahedral SOLID elements and it has been modelled with the same material than the column. Figure 4 shows the complete model for dynamic calculations. In both modal and dynamic analyses, the y axis match the direction of the impact and the $\mathrm{z}$ axis is vertical.

The ball was placed $1.2 \mathrm{~m}$ high from the upper part and $0.9 \mathrm{~m}$ far from the column. Starting in this position, the ball is released and, by the only force of gravity, the ball strikes the column and rebounds. Through this dynamic analysis we find, inter alia, the displacement of the all nodes and, in particular, of one node situated at the same height of the point of impact and in the exterior $\mathrm{x}$ surface of the column. This displacement is shown in figure 5 a).

The Fourier transform of the signal provides information about the main modes being excited with the impact. As can be seen in figure $5 \mathrm{~b}$ ), the vibration is monomodal and corresponds to the first mode of the vibration analysis (see Table 1). Monomodal vibrations are easy to analyze, since the movement can be described as an attenuated oscillation as

$$
x(t)=A e^{-\mu \cdot t} \sin (2 \pi f \cdot t+\phi)
$$

where $A$ is the amplitude of the oscillation, $f$ is the linear frequency, $\mu$ is the attenuation constant, and $\phi$ is a boundary constant. Data form the dynamic simulation has been fitted to (1) by a least squared method (LSM), thus obtaining the values in expression (2) for the parameters (with $95 \%$ confidence bounds), in which the subindex $d$ refers to the dynamic simulation, with a correlation coefficient $r^{2}=0.9917$. The confidence bounds are shown between brackets. 


$$
\begin{array}{ll}
\mathrm{A}_{d}=0.0933 \mathrm{~mm} & {[0.0936 \mathrm{~mm}, 0.0943 \mathrm{~mm}]} \\
\phi_{d}=-1.572 \mathrm{rad} & {[-1.575 \mathrm{rad},-1.568 \mathrm{rad}]} \\
\mu_{d}=14.67 \mathrm{~s}^{-1} & {\left[14.60 \mathrm{~s}^{-1}, 14.75 \mathrm{~s}^{-1}\right]} \\
f_{d}=66.7 \mathrm{~Hz} & {[66.5 \mathrm{~Hz}, 66.8 \mathrm{~Hz}]}
\end{array}
$$

\section{RESULTS}

The curve obtained from a single scan line (fig. 3), permits analyzing the vibration of the column. In figure $6 \mathrm{a}$, we show the curve obtained from one segment after re-slicing the video sequence of one impact. After computing the Fourier transform of this signal (figure 6b), we show that the oscillation can also be considered monomodal. The LSM fitting to equation (1) provides the values in expression (3), where subindex $s$ refers to single scan line, with a correlation coefficient of $r^{2}=0.9620$. The confidence bounds are shown between brackets.

$$
\begin{array}{ll}
\mathrm{A}_{s}=0.1005 \mathrm{~mm} & {[0.0943 \mathrm{~mm}, 0.1066 \mathrm{~mm}]} \\
\phi_{s}=7.536 \mathrm{rad} & {[7.47 \mathrm{rad}, 7.602 \mathrm{rad}]} \\
\mu_{s}=13.97 \mathrm{~s}^{-1} & {\left[12.33 \mathrm{~s}^{-1}, 15.61 \mathrm{~s}^{-1}\right]} \\
f_{s}=63.1 \mathrm{~Hz} & {[62.8 \mathrm{~Hz}, 63.4 \mathrm{~Hz}]}
\end{array}
$$

The selection of one single scan line (see figure 3 ) is subjected to the arbitrariness of the researcher. At high magnifications, the border profile appears rough. Moreover, the image can be affected of sun glares, scratches, irregularities, etc. In an attempt to eliminate this source of error, we have extended the study to a large number of segments. A large rectangle containing a big part of the vertical border in the target is selected and all the rows in this rectangle are analyzed. Only the data with a $r^{2}$ larger than 0.85 in the LSM fitting, have been analyzed. In practice, this means that around 320 line scans have been analyzed for each impact and only 5\% of the scanning lines have been rejected. We have obtained the mean and standard deviation of the parameters of eq. (1) for each impact. In table 2, the values obtained for the seven impacts performed are 
presented. The value for the constant $\phi$ has been omitted from the analysis since it is different for each scan line and it does not add any relevant physical information.

The results presented in eq. 3, which correspond to one single scan from Test 1, are slightly different to those in eq. 2 due to statistical variations. We would like to point out that results obtained through the high speed camera are in very good coincidence with those provided by the dynamic simulation in the three relevant parameters (amplitude, damping and vibration frequency), thus confirming the usefulness of the tool here developed.

In order to have an additional experimental confirmation of our results, the data obtained with the high speed camera have been compared with those provided by an accelerometer attached to the column. The impact was firstly monitorized with accelerometer A (Shock 350B03 PCB Piezotronics), with a measurement range of $\pm 10000 \mathrm{~g}$ and a frequency range from 0.4 to $10000 \mathrm{~Hz}$. The registered signal and its Fourier transform are plotted in figure 7a) and 7b), respectively.

One can see there that this impact is also monomodal but the registered mode is quite different from that obtained by the HS camera and the dynamic simulation. According to the results of the modal analysis of the column, the registered vibration corresponds to a combination of modes 11 to 13 in Table 1 . This vibration may come from an impact of the ball in a slightly deviated position from the center but, in any case, it is not the main vibration mode. The existence in the structure of the lowest mode at $64 \mathrm{~Hz}$ was checked in a second experiment by placing the accelerometer B (Structural 333B50 PCB Piezotronics), with a measurement range of $\pm 5 \mathrm{~g}$ and a frequency range from 0.5 to $3000 \mathrm{~Hz}$. A weak impact in the same place but with an Impulse Force Hammer (Kistler, type 9728A20000) was performed and the registration of the fundamental mode was possible. 
The question that arises here is why there is no evidence of the first mode in the acceleration signal registered with accelerometer A. Assuming monomodal vibration, the acceleration can be calculated from the second derivative of expression (1):

$$
a=A e^{-\mu \cdot t}\left[\left(\mu^{2}-(2 \pi f)^{2}\right) \sin (2 \pi f \cdot t+\phi)+4 \pi \mu f \cos (2 \pi f \cdot t+\phi)\right]
$$

For the measured values of $A, f$ and $\mu$ shown in Table 2 , the calculated acceleration through eq. 4 gives an absolute maximum peak of $1.5 \times 10^{4} \mathrm{~mm} / \mathrm{s}^{2}(1.5 \mathrm{~g})$. A careful analysis of the signal shows that the dark current in the accelerometer A measuring setup provoked impulsional noise of amplitude $\pm 5 \mathrm{~g}$, which masks the acceleration due to the lowest mode $(1.5 \mathrm{~g})$.

For the impact here performed, the accelerometer A is not capable of registering the acceleration due to the lowest mode while the accelerometer B is not capable of giving a good signal but a saturated one. Although this could be solved by correct selection of the accelerometer, in many cases the maximum expected acceleration is unknown so a correct prior election is not always possible. Even it may happen that measurements can only be taken in one single session and the system has to be robust enough to provide good results with only one trial.

The situation here described illustrates one of the advantages of our system. The amplitude of acceleration linearly depends on the square of the frequency for low damping constants. This effect is especially noticeable when strong impacts occur and many modes are excited at the same time. Since acceleration based devices are very sensitive to high frequencies, the lowest modes, which produce the highest displacements, can be masked and interpretation of the signal may lead to wrong conclusions.

Otherwise, it should be noted that, since the sampling frequency of the camera is set to $1000 \mathrm{~Hz}$, it is not able to register the movement associated with the frequency of 1200 
$\mathrm{Hz}$, as it is shown in figure $7 \mathrm{~b}$. However, as can be seen in table 1 , all the movements with a frequency around $1200 \mathrm{~Hz}$ are rhomboidal deformations of the section; then the movement of the target is in the direction of the optical axis of the camera, and thus it is not visible with the actual setup. Moreover, in the finite element simulation, this 1200 $\mathrm{Hz}$ frequency does not appear due to the complete symmetry of the impact, unlike the reality, in which small deviation of the ball during its fall can cause this kind of movements.

\section{APPLICATIONS}

The system here presented has been used in a real scale experiment for testing building structures under low speed car impacts [21]. The aim of the experiment was to register the maximum displacement and vibration modes of a concrete column. This parameter is important for analyzing the stresses on the structure under dynamic loading [2] and to determine its integrity. In figure 8 , we show a picture of the crash test together with the displacement registered by the camera. The column was monitorized through several accelerometers (ACC), linear displacement sensors (LDS) and the high speed camera (HSC). Accelerometers and linear displacement sensors were screwed to the column. LDS were also hold by a parallel structure. For safety reasons and in order to avoid influence from ground vibration the camera was situated at $2.5 \mathrm{~m}$ away from the column. Accelerometers provided valuable information about vibration modes, but the noise in the signal did not allow double integration for displacement calculation. Linear displacement sensors also failed, since the parallel structure to which they were attached was too close to the column and it was influenced by the ground vibrations. Only data obtained from the camera were reliable and allowed us to obtain the maximum displacement (Table 3). Vibration frequencies obtained from the camera were in 
coincidence with those obtained with the accelerometers (Table 4). Notice that in both tables, there are empty cells. Those are measurements where signal noise impeded obtaining a clear result.

Crash tests were conducted for experimentally testing the parameters established by the Eurocode 1 [3]. We can see that, in general, LDS are not reliable for measuring the displacement of a structure. Although provided displacements are of the same order of magnitude than those obtained with the camera, the lack of repeatability makes them inaccurate for our proposal. The reader should notice the good coincidence between the frequency registered by the camera and by the accelerometers. It is remarkable that accelerometer at the impact point (0.6 meters) did not work correctly, probably due to the violence of the car crash. These facts confirm that, for some applications, image based non contact methods are more robust than traditional electronic systems.

\section{CONCLUSIONS}

We have used an image based method for non contact measurement of displacements and vibrations on a structure. Images of an impact were recorded with a high speed camera at 1000 fps. A convenient re-slicing of the video sequence allows direct visualization of the structure displacement and obtaining the main parameters of the vibrating movement. In order to have some reference data about the real movement of the column, we used some accelerometers and we did a finite element model which reflects the actual behavior of the column. The obtained results through the re-slicing of the video sequence were successfully compared with those obtained from a FEM model and showed to be consistent with accelerometers, thus showing the accuracy of the procedure. 
The method can overcome a common limitation of the accelerometer for registering low frequencies under strong impacts and avoids the need for adequate a priori choice of the accelerometer, when the maximum acceleration of the signal to be recorded is unknown. This is very important when there is only one opportunity of measuring. Furthermore, with this technique, double integration of the acceleration for displacement calculation is not needed.

This method can be useful in the measurement of displacement of structures as bridges under rail traffic, buildings under earthquake or slender structures subjected to the wind, where contact measurements are difficult or even impossible. Determination of the accuracy of the method is difficult, due to the variety of situations where it can be applicable. An adequate combination of the CCD resolution, the objective and the distance to the target will determine the performance of the method and the limitation of the system. These parameters have to be adjusted according to the expected displacement distances. As a rule of thumb, the system has to be able to detect displacements of at least 2 pixels. Detection below this limit will not be reliable and the method will not be applicable.

Although the camera here used is somehow expensive, the same experiment can be implemented with a camera taking $200 \mathrm{fps}$, thus making a low cost, fast and accurate method to analyze the movement of a structure.

The distinctiveness fact that the movement of the studied point can be directly seen with a simple procedure helps very much to interpret results. All this features make this method interesting and powerful to the study of the behavior of the structures during dynamic excitation. 


\section{REFERENCES}

[1] Gentile C, Saisi A. Ambient vibration testing of historic masonry towers for structural identification and damage assessment. Constr Build Mater. 2007 Jun 21; 6: $1311-1321$

[2] Chopra AK 2001. Equations of Motion, Problem Statement and Solution Methods. In Stenquist B, Scherwatzky K, editors. Dynamic of structures: Theory and applications to earthquake engineering, $2^{\text {nd }}$ Ed., New Jersey: Prentice-Hall, Englewood Cliffs; 2001. p. 23-25.

[3] Eurocode 1: Actions on structures - Part 2-7: Accidental actions due to impact and explosions. ENV 1991-2-7, European committee for Standardization, June 1998.

[4] Minimun Design Loads for Buildings and Other Structures. ASCE STANDARD, ASCE/SEI 7-05, American Society of Civil Engineers, 2006.

[5] Park KT, Kim SH, Lee KW. Eng Struct. 2005; 27: 371-8.

[6] Yang J, Li JB, Lin G. Soil Dyn Earthq Eng. 2006; 26: 725-734.

[7] Stiros SC. Soil Dyn Earthq Eng. 2008; 28: 415-420.

[8] Cunha A, Caetano E, Delgado R. J Bridge Eng ASCE. 2001; 6(1): 54-62.

[9] Nassif HN, Gindy M, Davis J. NDT \& E Int. 2005; 38(3): 213-128

[10] Pieraccini M, Fratini M, Parrini F, Atzeni C, Bartoli G. NDT \& E Int. Jun. 2008; 41(4): 258-264.

[11] Gentile C, Bernardini G. NDT \& E Int. 2008; 41(7): 544-553.

[12] Castellini P, Martarelli M, Tomasini EP. Mech syst signal pr. 2006; 20: 1265-1285.

[13] Bartoli G, Facchini L, Pieraccini M, Fratini M, Atzeni C. Struct. Control Health Monit. Apr. 2008; 15 (3): 283-298.

[14] Pieraccini M, Fratini M, Parrini F, Atzeni C. IEEE T Geosci Remote Sens. Nov. 2006; 40 (11): 3284-3288. 
[15] Nickitopoulou A, Protopsalti K, Stiros S. Eng Struct. Aug. 2006; 28 (10): 14711482.

[16] Hack E, Leroy D. Opt Lasers Eng. 2005; 43: 455-474.

[17] Wahbeh AM, Caffrey JP, Masri SF. Smart Mater Struct. 2003; 12: 785-794

[18] Lee JJ, Shinozuka M. NDT \& E Int. 2006; 39: 425-431.

[19] Image Processing and analysis with Java, http://rsb.info.nih.gov/ij/

[20] LS-DYNA Keyword user's manual, version 970. (C) Livermore Software Technology Corporation. April 2003.

[21] Ferrer B, Ivorra S, Irles R, Mas D, Real size experiments of car crash against building column, $11^{\text {th }}$ International Conference on Structures Under Shock and Impact (SUSI 2010), Tallin (Estonia), July 2010. 




FIGURE 1 The steel column under analysis. $155 \times 207 \mathrm{~mm}(314 \times 314$ DPI $)$ 


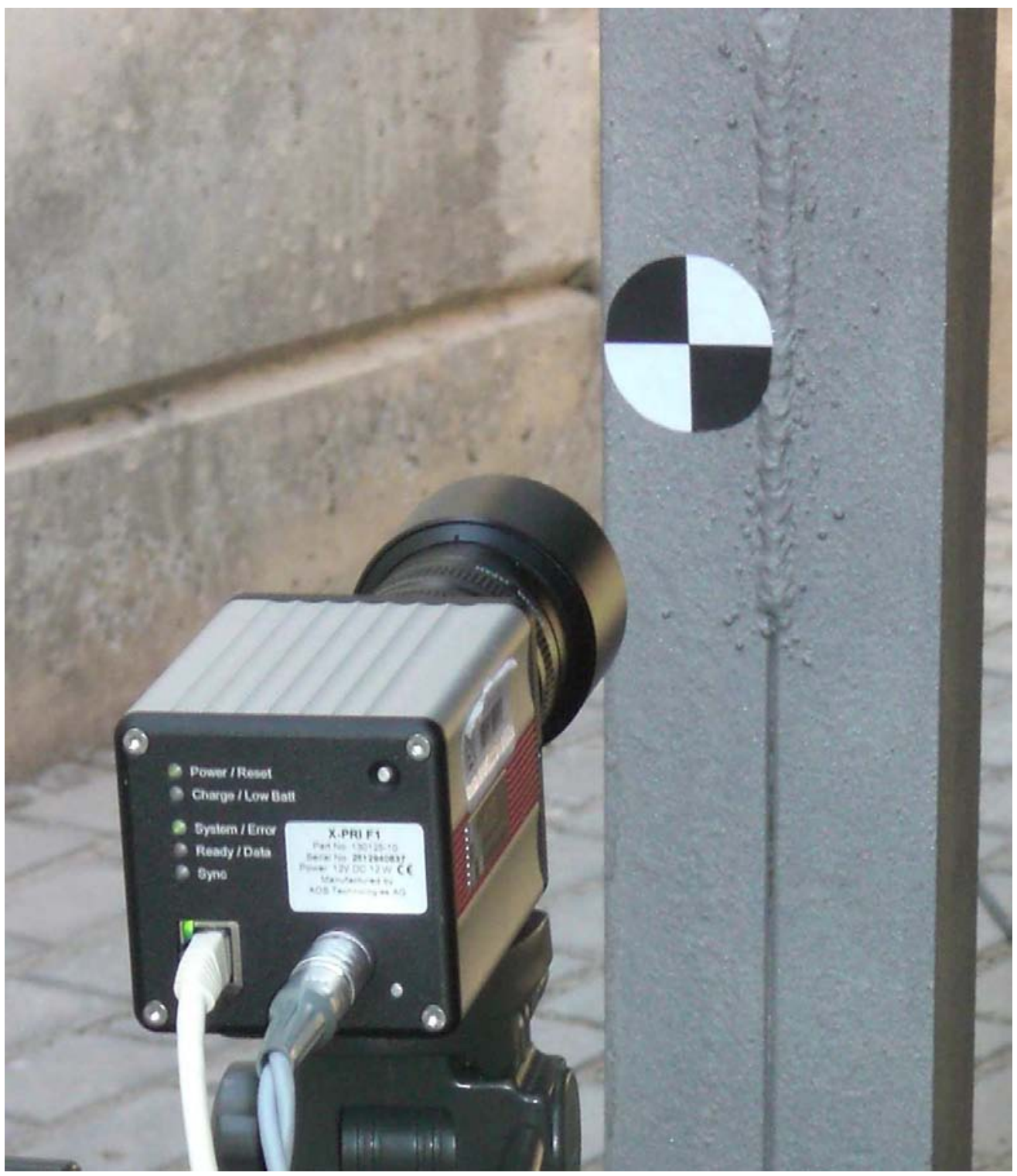

FIGURE 2 The high speed camera pointing to the target. The accelerometer is hidden at the left part of the column. $430 \times 497 \mathrm{~mm}(72 \times 72 \mathrm{DPI})$ 


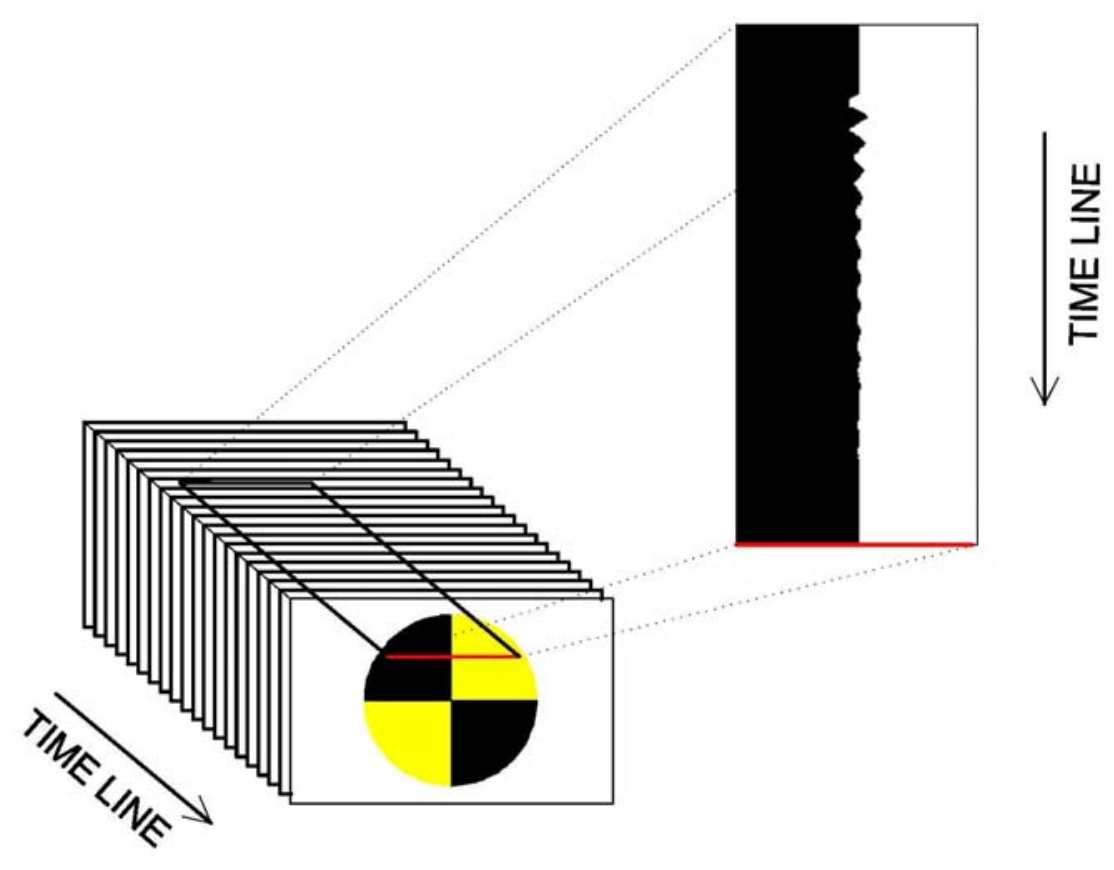

FIGURE 3 Schematic representation of the process followed to obtain a re-sliced sequence. The video frames are stacked in a hypermatrix. A transversal plane is then extracted from the structure thus showing the time variations of the image section.

$74 \times 52 \mathrm{~mm}(600 \times 600 \mathrm{DPI})$ 


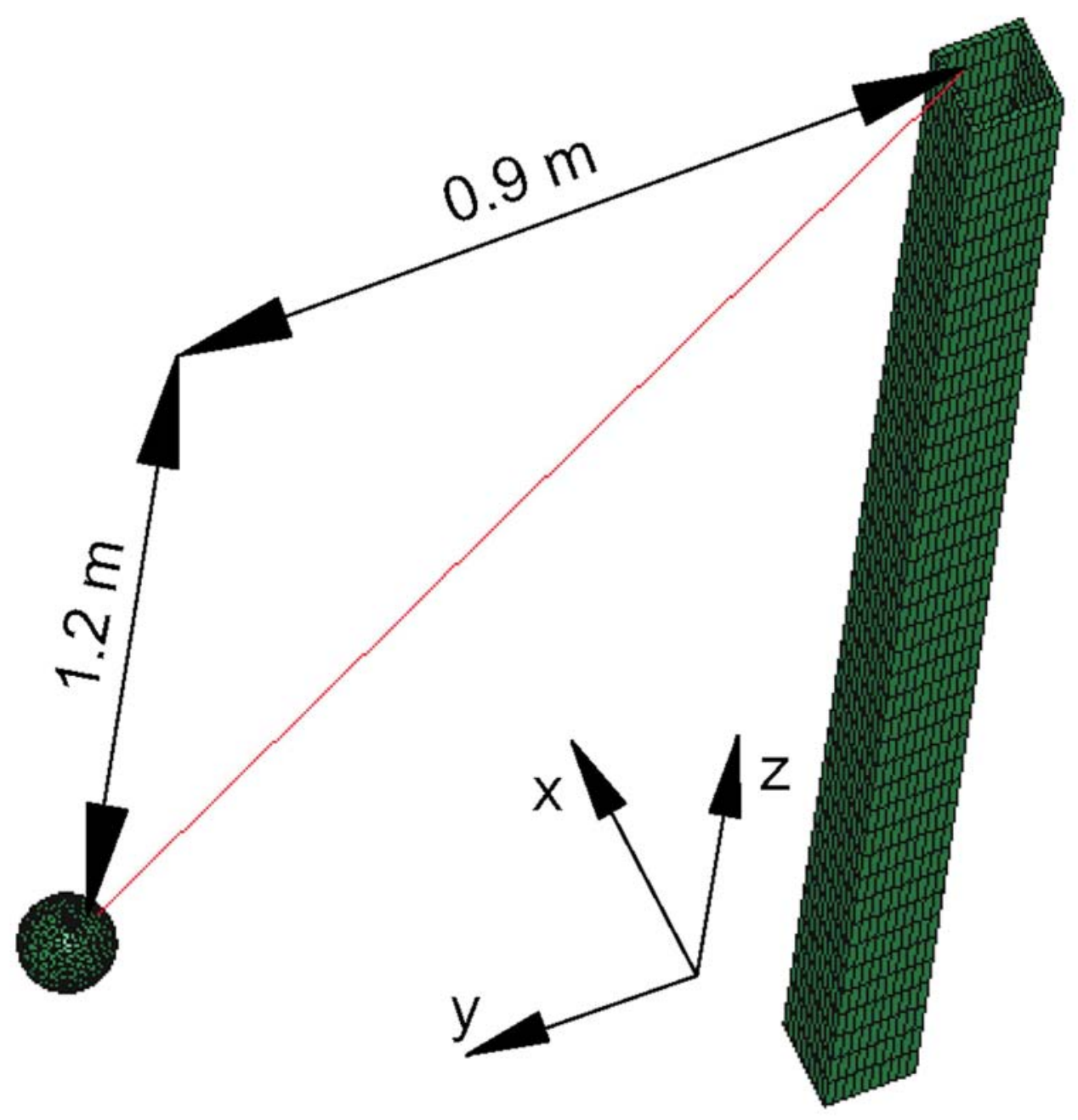

FIGURE 4 Schematic representation of the experiment for the dynamic simulation $110 \times 113 \mathrm{~mm}(600 \times 600 \mathrm{DPI})$ 

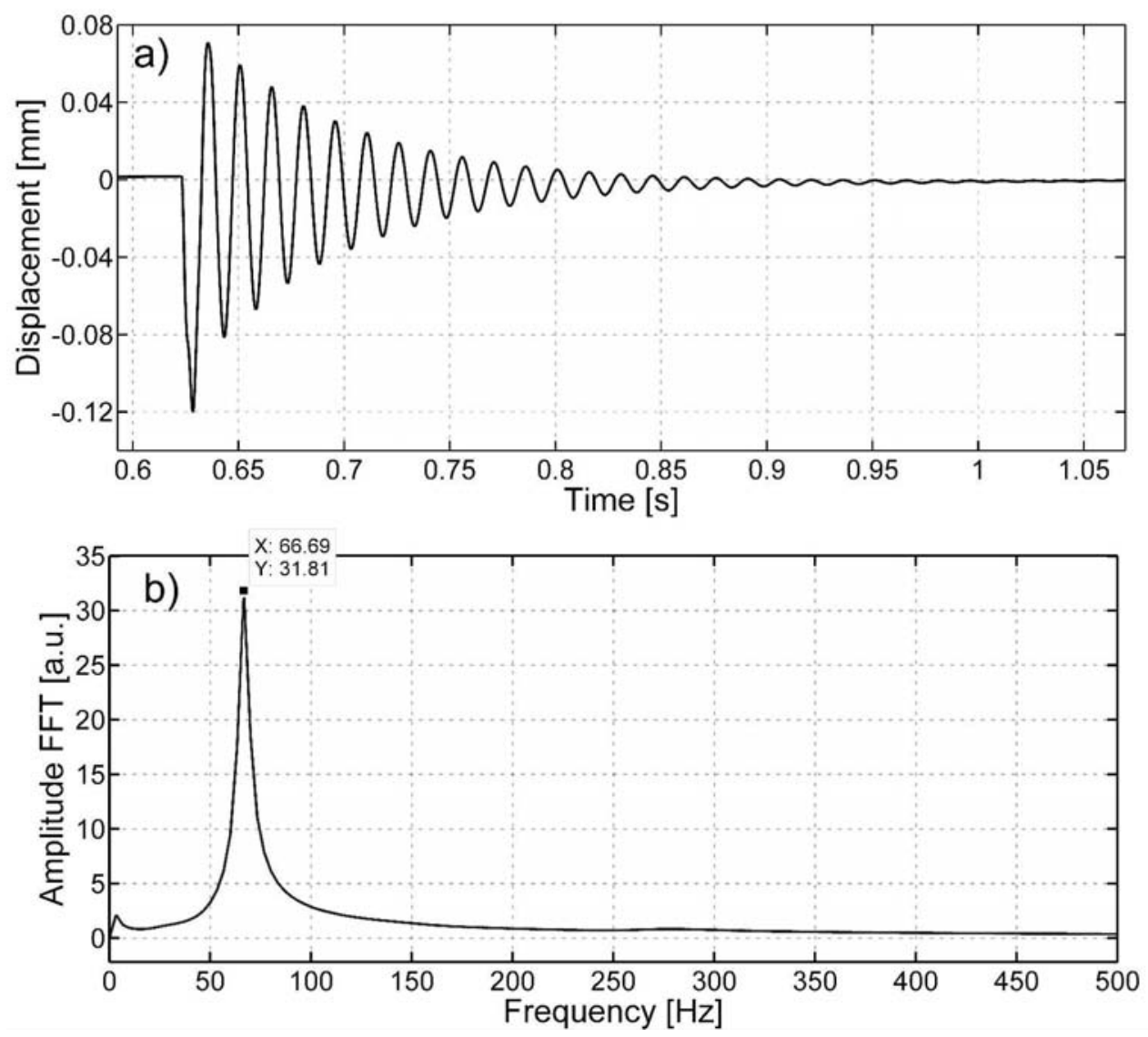

FIGURE 5 Data from dynamic simulation. a) Displacement of a column node situated on the opposite surface of the impact point. b) Fourier transform of the signal in a). $199 \times 176 \mathrm{~mm}(600 \times 600 \mathrm{DPI})$ 

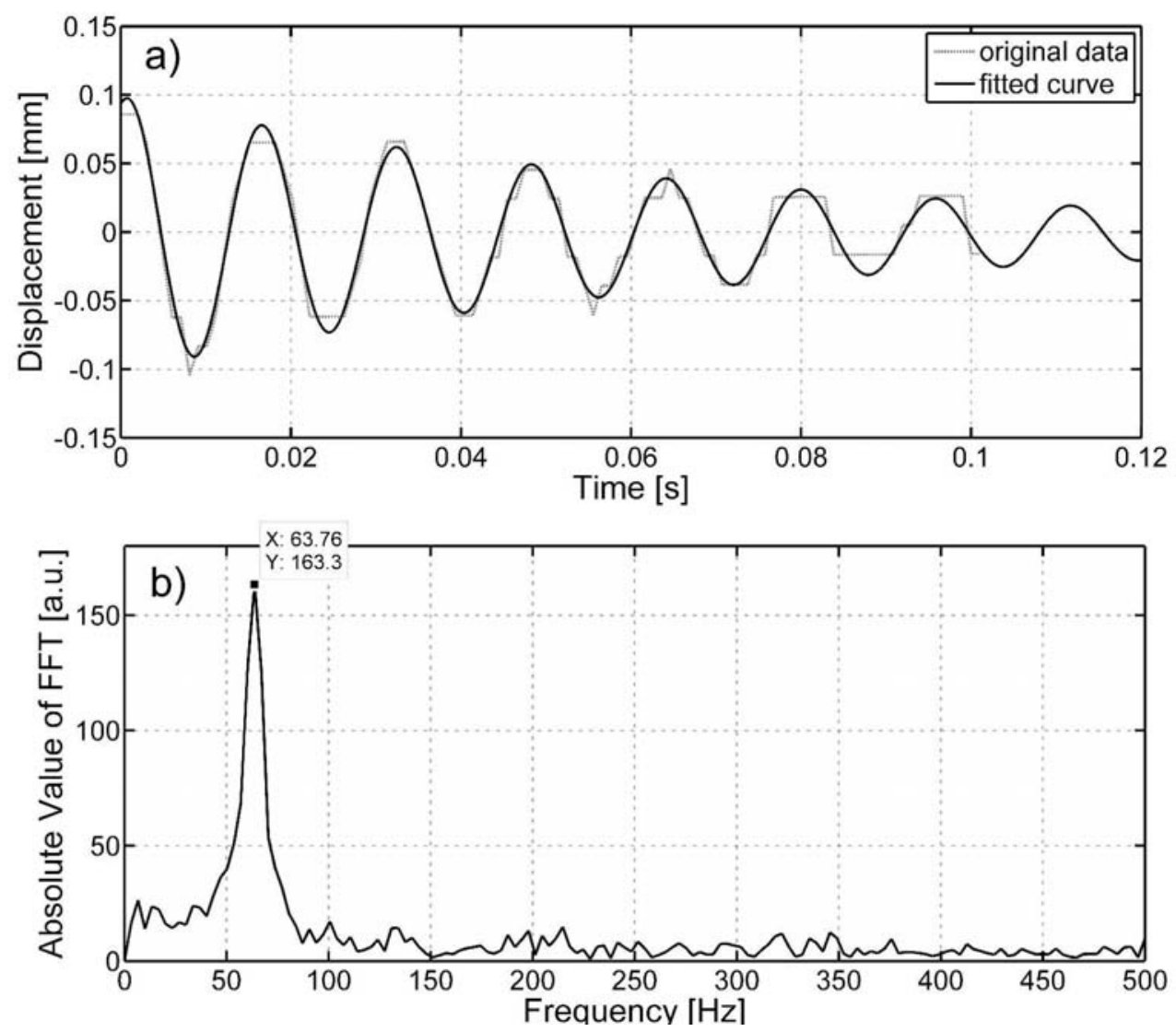

FIGURE 6 Data from image processing. a) Amplitude of movement of the target obtained through a scan line. b) Fourier transform of the signal in a) $199 \times 172 \mathrm{~mm}(600 \times 600 \mathrm{DPI})$ 

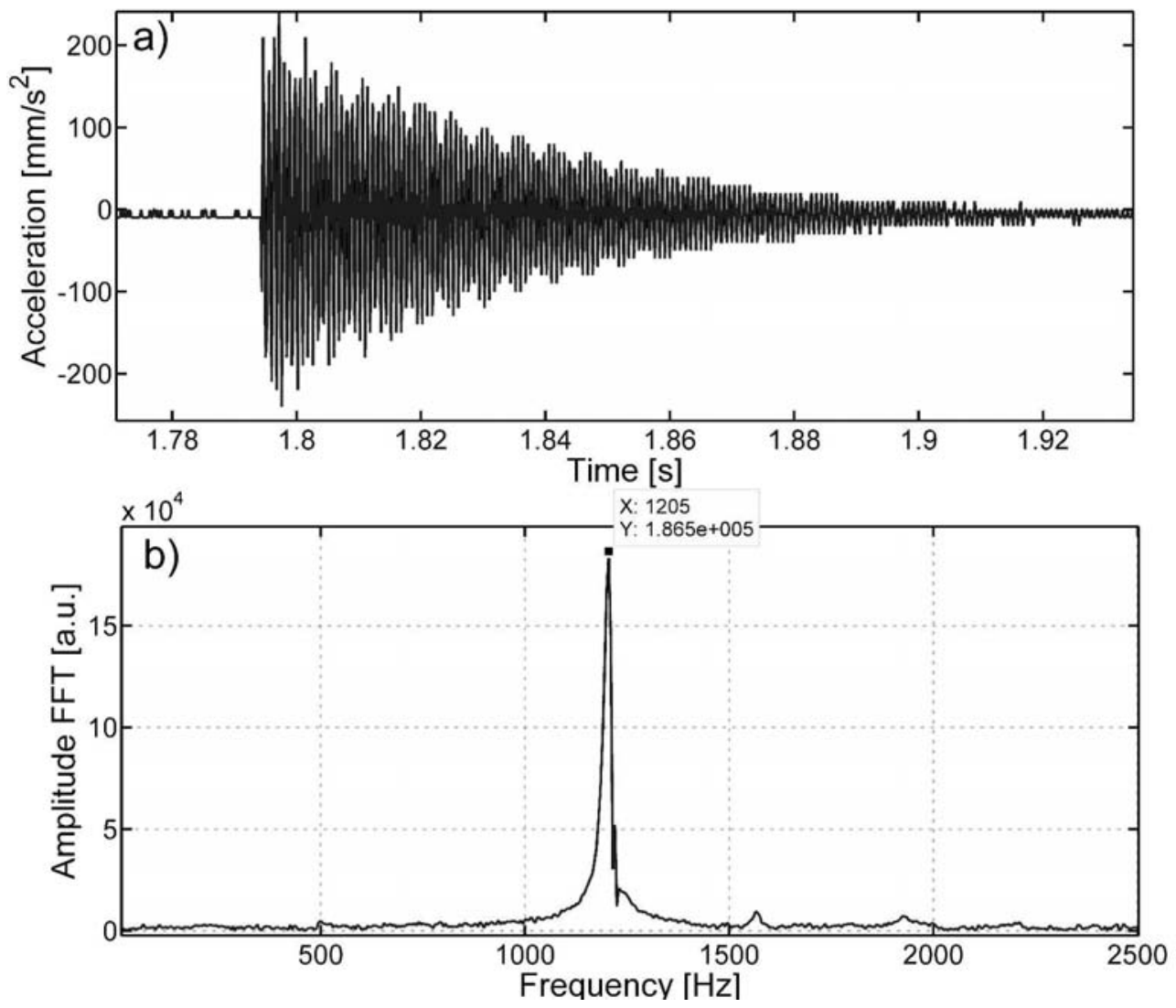

FIGURE 7 Data from accelerometer $A$. a) Signal recorded b) Fourier transform of the signal in a) $199 \times 172 \mathrm{~mm}(600 \times 600 \mathrm{DPI})$ 

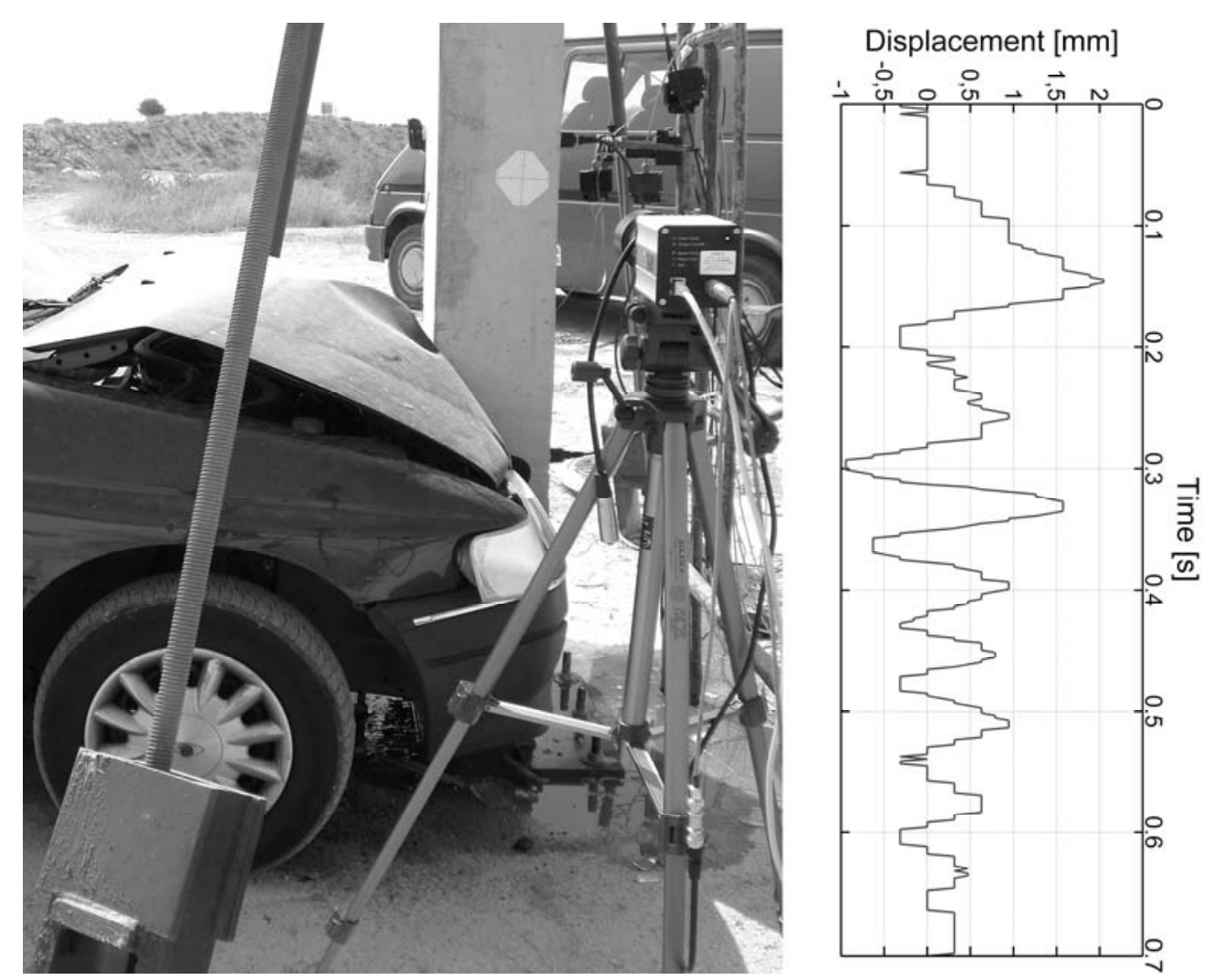

FIGURE 8 Impact test of structural response under low-speed impacts. The figure shows the displacement registered by the camera. $199 \times 160 \mathrm{~mm}(600 \times 600 \mathrm{DPI})$ 


\begin{tabular}{|c|c|c|}
\hline MODE & $\begin{array}{c}\text { FREQUENCY } \\
(\mathrm{Hz})\end{array}$ & DESCRIPTION OF MOVEMENT \\
\hline 1 & 66.87 & Displacement, y direction, $1 / 2$ wavelenght \\
\hline 2 & 71.21 & Displacement, $\mathrm{x}$ direction, $1 / 2$ wavelenght \\
\hline 3 & 261.31 & Displacement, y direction, 1 wavelenght \\
\hline 4 & 274.92 & Displacement, $\mathrm{x}$ direction, 1 wavelenght \\
\hline 5 & 566.36 & Displacement, y direction, $3 / 2$ wavelenght \\
\hline 6 & 584.84 & Displacement, $\mathrm{x}$ direction, $3 / 2$ wavelenght \\
\hline 7 & 662.67 & Torsion, $\mathrm{z}$ direction, $1 / 2$ wavelenght \\
\hline 8 & 957.76 & Displacement, y direction, 2 wavelenght \\
\hline 9 & 966.00 & Displacement, $\mathrm{x}$ direction, 2 wavelenght \\
\hline 10 & 1044.35 & Displacement, $\mathrm{z}$ direction, 2 wavelenght \\
\hline 11 & 1194.66 & Rhomb shape, plane $\mathrm{x}=\mathrm{y}, 1$ wavelenght \\
\hline 12 & 1201.42 & Rhomb shape, plane $\mathrm{x}=\mathrm{y}, 1$ wavelenght \\
\hline 13 & 1280.79 & Rhomb shape, plane $x=y, 3 / 2$ wavelenght \\
\hline 14 & 1345.35 & Torsion, $\mathrm{z}$ direction, 1 wavelenght \\
\hline 15 & 1381.54 & Displacement, y direction, 5/2 wavelenght \\
\hline 16 & 1407.67 & Displacement, $\mathrm{x}$ direction, $5 / 2$ wavelenght \\
\hline 17 & 1415.57 & Rhomb shape, plane $\mathrm{x}=\mathrm{y}, 2$ wavelenght \\
\hline 18 & 1631.95 & Rhomb shape, plane $\mathrm{x}=\mathrm{y}, 2$ wavelenght \\
\hline 19 & 1797.75 & Displacement, $\mathrm{x}$ direction, 3 wavelenght \\
\hline 20 & 1885.34 & Displacement, y direction, 3 wavelenght \\
\hline
\end{tabular}

TABLE 1 Vibration modes for the steel column in the finite element model. In the right column the vibration is described by giving the type of movement, its direction and the number of waves included in the total column length. 


\begin{tabular}{cccc}
\hline & $\mathrm{A}(\mathrm{mm})$ & $\mu\left(\mathrm{s}^{-1}\right)$ & $f(\mathrm{~Hz})$ \\
\hline Test 1 & $0.097 \pm 0.005$ & $15.2 \pm 1.2$ & $62.9 \pm 0.1$ \\
\hline Test 2 & $0.090 \pm 0.004$ & $16.6 \pm 1.5$ & $63.1 \pm 0.1$ \\
\hline Test 3 & $0.098 \pm 0.005$ & $15.0 \pm 1.3$ & $62.8 \pm 0.2$ \\
\hline Test 4 & $0.099 \pm 0.005$ & $15.1 \pm 1.5$ & $62.8 \pm 0.2$ \\
\hline Test 5 & $0.099 \pm 0.003$ & $15.0 \pm 1.2$ & $62.6 \pm 0.1$ \\
\hline Test 6 & $0.101 \pm 0.004$ & $15.6 \pm 1.1$ & $62.5 \pm 0.1$ \\
\hline Test 7 & $0.102 \pm 0.004$ & $15.1 \pm 1.0$ & $62.5 \pm 0.1$ \\
\hline Average & $0.098 \pm 0.004$ & $15.1 \pm 1.3$ & $62.7 \pm 0.2$ \\
\hline
\end{tabular}

TABLE 2 Average results from 320 (approx) scan lines for the different tests performed. 


\begin{tabular}{cccccc}
\hline \multirow{2}{*}{$\begin{array}{c}\text { Height } \\
(\mathbf{m})\end{array}$} & \multirow{2}{*}{ Sensor } & \multicolumn{4}{c}{ Maximum registered displacement $(\mathbf{m m})$} \\
\cline { 3 - 6 } & & $\mathbf{1}^{\text {st }} \mathbf{i m p .}$ & $\mathbf{2}^{\text {nd }} \mathbf{i m p .}$ & $\mathbf{3}^{\text {rd }}$ imp. & $\mathbf{4}^{\text {th }}$ imp. \\
\hline $\mathbf{2 . 7 5}$ & LDS & 2.1 & 1.2 & 2.7 & 1.8 \\
\hline $\mathbf{1 . 8 5}$ & LDS & -- & 4.4 & 5.7 & 3.8 \\
\hline $\mathbf{1 . 3}$ & LDS & 3.8 & 1.8 & 2.6 & 1.7 \\
\hline $\mathbf{1 . 3}$ & HSC & 1.8 & 2.1 & 2 & 1.8 \\
\hline
\end{tabular}

TABLE 3 Maximum displacement registered in each impact and in each point of the column. 


\begin{tabular}{|c|c|c|c|c|c|}
\hline \multirow{2}{*}{$\begin{array}{c}\text { Height } \\
\text { (m) }\end{array}$} & \multirow{2}{*}{ Sensor } & \multicolumn{4}{|c|}{ Frequency (Hz) } \\
\hline & & $1^{\text {st }}$ imp. & $2^{\text {nd }}$ imp. & $3^{\text {rd }}$ imp. & $4^{\text {th }}$ imp. \\
\hline \multirow{2}{*}{2.75} & $\mathrm{ACC}$ & $18.5 ; 67.6$ & $17.2 ; 63.6$ & $17.3 ; 63.8$ & $17.5 ; 64.4$ \\
\hline & LDS & $18.5 ; 44.2$ & 17.2 & 24.3 & 21.3 \\
\hline \multirow{2}{*}{1.85} & $\mathbf{A C C}$ & $18.5 ; 67.6$ & $17.5 ; 64.8$ & $17.3 ; 64$ & $17.5 ; 64.4$ \\
\hline & LDS & --- & 17.19 & 24.3 & 21.3 \\
\hline \multirow{3}{*}{1.3} & $\mathrm{ACC}$ & $18.5 ; 67.6$ & --- & --- & --- \\
\hline & LDS & $44.2 ; 56.9$ & 17.16 & 24.13 & 21.7 \\
\hline & HSC & $18 ; 67$ & $17.3 ; 64$ & $17.3 ; 64$ & $17.5 ; 64$ \\
\hline \multirow{2}{*}{0.6} & $\mathrm{ACC}$ & $18.5 ; 67.6$ & $17.4 ; 64.4$ & 62.78 & $17.4 ; 20.7$ \\
\hline & LDS & $44.2 ; 56.9$ & --- & --- & --- \\
\hline
\end{tabular}

TABLE 4 Frequencies in each impact and in each point of the column. 